\title{
Correction to: On the concept of $B$-statistical uniform integrability of weighted sums of random variables and the law of large numbers with mean convergence in the statistical sense
}

\section{Manuel Ordóñez Cabrera ${ }^{1}$ - Andrew Rosalsky ${ }^{2}$. Mehmet Ünver ${ }^{3}$. Andrei Volodin 4}

Published online: 22 November 2021

(c) The Author(s) under exclusive licence to Sociedad de Estadística e Investigación Operativa 2021

\section{Correction to: TEST 30, 83-102 (2021) https://doi.org/10.1007/s11749-020-00706-2}

Professor Lê Văn Thành (Vinh University, Nghe An, Viet Nam) has so kindly called to the authors' attention an error in their original article. On line 6 of page 89, the authors incorrectly asserted in the proof of (i) in the necessity half of Theorem 1 that

$$
\left\{n \in \mathbb{N}: \sum_{k=1}^{\infty}\left|a_{n k}\right| E\left|X_{k}\right| I_{\left\{\left|X_{k}\right| \leq a\right\}}>a\right\}=\varnothing .
$$

The argument for establishing (i) is corrected as follows.

By (2), we can choose $M$ such that

$$
\sup _{n \in \mathbb{N}} \sum_{k=1}^{\infty}\left|a_{n k}\right|<M<\infty .
$$

The original article can be found online at https://doi.org/10.1007/s11749-020-00706-2.

$凶$ Andrew Rosalsky

rosalsky@stat.ufl.edu

1 Department of Mathematical Analysis, University of Seville, 41080 Sevilla, Spain

2 Department of Statistics, University of Florida, Gainesville, FL 32611, USA

3 Department of Mathematics, Faculty of Science, Ankara University, 06100 Ankara, Turkey

4 Department of Mathematics and Statistics, University of Regina, Saskatchewan S4S 0A2, Canada 
Note that with $a>0$ as in (4),

$$
\begin{aligned}
\{n & \left.\in \mathbb{N}: \sum_{k=1}^{\infty}\left|a_{n k}\right| E\left|X_{k}\right|>M a+\frac{\varepsilon}{2}\right\} \\
& \subset\left\{n \in \mathbb{N}: \sum_{k=1}^{\infty}\left|a_{n k}\right| E\left|X_{k}\right| I_{\left\{\left|X_{k}\right| \leq a\right\}}>M a\right\} \\
& \bigcup\left\{n \in \mathbb{N}: \sum_{k=1}^{\infty}\left|a_{n k}\right| E\left|X_{k}\right| I_{\left\{\left|X_{k}\right|>a\right\}}>\frac{\varepsilon}{2}\right\} \\
& \subset\left\{n \in \mathbb{N}: \sum_{k=1}^{\infty}\left|a_{n k}\right|>M\right\} \\
& \bigcup\left\{n \in \mathbb{N}: \sum_{k=1}^{\infty}\left|a_{n k}\right| E\left|X_{k}\right| I_{\left\{\left|X_{k}\right|>a\right\}}>\frac{\varepsilon}{2}\right\} .
\end{aligned}
$$

Combining (*), (4), and (**), we obtain that

$$
\begin{aligned}
0 \leq & \delta_{B}\left(\left\{n \in \mathbb{N}: \sum_{k=1}^{\infty}\left|a_{n k}\right| E\left|X_{k}\right|>M a+\frac{\varepsilon}{2}\right\}\right) \\
\leq & \delta_{B}\left(\left\{n \in \mathbb{N}: \sum_{k=1}^{\infty}\left|a_{n k}\right|>M\right\}\right) \\
& +\delta_{B}\left(\left\{n \in \mathbb{N}: \sum_{k=1}^{\infty}\left|a_{n k}\right| E\left|X_{k}\right| I_{\left\{\left|X_{k}\right|>a\right\}}>\frac{\varepsilon}{2}\right\}\right) \\
= & 0+0=0
\end{aligned}
$$

and so

$$
\delta_{B}\left(\left\{n \in \mathbb{N}: \sum_{k=1}^{\infty}\left|a_{n k}\right| E\left|X_{k}\right|>M a+\frac{\varepsilon}{2}\right\}\right)=0 .
$$

Thus, the real number $M a+\frac{\varepsilon}{2}$ is a $B$-statistical upper bound of the sequence $\left\{\sum_{k=1}^{\infty}\left|a_{n k}\right| E\left|X_{k}\right|: n \in \mathbb{N}\right\}$. Hence (i) holds.

Acknowledgements The authors are grateful to Professor Thành for calling to their attention the error in the proof of (i), for his comments which enabled the authors to improve the presentation of their initial correction of the error, and for his interest in their work.

Publisher's Note Springer Nature remains neutral with regard to jurisdictional claims in published maps and institutional affiliations. 